\title{
Scientific-practical results of monitoring anthropogenic influence upon environment of mining territories
}

\author{
Nikolay Kachurin ${ }^{1}$, Vitaliy Komaschenko ${ }^{2}$, Vladimir Golik ${ }^{3}$, and Volodymyr Morkun ${ }^{4 *}$ \\ ${ }^{1}$ Tula State University Department of Geotechnologies and Underground Constructions, 92 Lenina \\ Ave., 300012 Tula, Russia \\ ${ }^{2}$ Belgorod State National Research University, Trade-union St., 117485 Belgorod, Russia \\ ${ }^{3}$ North Caucasus Mining Metallurgical Institute, 85 Pobedy St., 308015 Vladikavkaz, Russia \\ ${ }^{4}$ Kryvyi Rih National University, Computer Science, Automation and Control Systems Department, \\ 11 Vitalii Matusevych St., 50027 Kryvyi Rih, Ukraine
}

\begin{abstract}
The objective of this paper is to improve the ecological monitoring system and to take effective technological measures by way of wastes neutralization. The scientific-practical results of monitoring the anthropogenic influence upon the environment of mining-industrial territories were discussed. The global environmental problems of modernity are connected only with the anthropogenic pollution of the atmosphere. Pollution by hazardous substances at various enterprises harms health and disrupts the dynamic balance of natural systems. It is especially typical for mining-industrial region territories. The solution of the problem of environmentally optimal distributing resources for industrial enterprises of the mining-industrial region will allow making maximal profit from each enterprise by assumption of reducing anthropogenic influence upon environment up to the maximum permissible value, which is specified by normative documents. The patterns of formation of mining enterprises influence consequences on the atmosphere have been improved with the use of experimental and theoretical studies and in order to optimize the resources distribution for preventive measures, which can ensure the atmospheric safety of the mining-industrial region. The proposed methodological principles for a comprehensive assessment of the atmosphere of the miningindustrial region allow to implement an integrated approach to forecasting the intensity of atmospheric pollution, the economic efficiency of production and atmospheric air condition control, using the basic requirements of the environmental imperative for the territory under consideration.
\end{abstract}

\section{Introduction}

Increasing scale of environmental influencing imparts special topicality for problem of creating adequate environmental-economical mathematical models. Increasing scale of anthropogenic influence upon natural environment and its negative consequences and else

*Corresponding author: pikilnyak@gmail.com 
possibilities of optimizing this influencing require in-depth study. The search of scientific substantiated forms and scale of industrial human activity providing rational using natural resources and getting necessity useful productions without pernicious influence upon natural environment acquires specific significance $[1-10]$.

Provisional evaluations show that long-range planning without taking into account environmental effects is impossible. On the other hand, existing environmental models have specific character and are impossible to reflect complex interconnections but can show consequences of anthropogenic influences. For example, Kuznetsk Basin (Russia) coal industry influences upon environment essentially. Retrospective analyzing and statistical evaluating show that intensity of anthropogenic influencing Company "Prokop'evskugol"" enterprises upon atmosphere is equal to $6-7 \mathrm{~kg}$ of dust-gas emission per 1 ton of produced coal $[11-15]$.

\section{Materials and methods}

There are three stages of the process getting and using knowledge. These are observation, mathematical modelling and evaluating adequacy. Scheme of the process getting and using knowledge about the environmental condition of the concerned territory is universal [1619].

The conceptual formula has the following form: $R_{E N V}=P_{A N T} D$, where $R_{E N V}, P_{A N T}$ are risk and probability negative anthropogenic influence to environment accordingly; $D$ is the detriment of negative anthropogenic influence to the environment. This formula can be written in the following form:

$$
R_{E N V}=P\left\{I_{I N F}>M_{P E L}\right\} P_{G L} D,
$$

where $I_{I N F}$ is the intensity of negative anthropogenic influence to the environment; MPEL is a maximal level of influence to the environment; $P\left\{I_{I N F}>M_{P E L}\right\}$ is the probability of appearance negative anthropogenic influence to the environment, which more than maximal level; $P_{G L}$ is the probability of failure at the environmental protection system.

The detriment of negative anthropogenic influence to the environment has the following form:

$$
D=\int_{\Omega} p_{P o p}(x, y, z) P_{I n h}(x, y, z) d \Omega,
$$

where $p_{P o p}(x, y, z)$ and $P_{I n h}(x, y, z)$ are accordingly distribution of population density of at the concerned territory and probability of negative influence to inhabitants in all zone of negative anthropogenic influence to the environment; $\Omega$ is a zone of negative anthropogenic influence to the environment.

The basic theoretical principle is the realization of arrangements, which allow providing follow environmental conditions. The theoretical function of distribution identifies the probability that life-activity without environmental conditions infringements is less than the specified time. It's time of environmentally favourable life-activity. Consequently, the basic theoretical principal can be formulated follow form. The theoretical function of distribution identifies the probability that life-activity without environmental conditions infringements is less than specified time $t$ (time of environmentally favourable life-activity) that is why:

$$
P\left\{I_{I N F}>M_{P E L}\right\} \times P_{G L}=1-Q\{T<t\},
$$

where $Q$ and $T$ are probability and period of the life-activity for concerned territory without 
environmental infringements distribution law of probability for life-activity in concerned territory without environmental infringements has the following form:

$$
Q(t)=\exp \left[-\int_{0}^{t} \lambda(\tau) d \tau\right]
$$

where $Q$ and $\lambda$ are the probability of the life-activity for concerned territory without environmental infringements and intensity of the times on negative anthropogenic influence to environment accordingly.

Period of time when the life-activity for concerned territory without environmental infringements can be written in the following view:

$$
T=\int_{0}^{\infty}\left\{\exp \left[-\int_{0}^{t} \lambda(\tau) d \tau\right]\right\} d t
$$

The problem of managing the environmental safety of life-activity at the concerned territory is the realization of arrangements, which allows providing follow conditions:

$$
R \rightarrow \min ; Q \rightarrow \max ; T \rightarrow \max ; \int_{0}^{t} \lambda(\tau) d \tau \rightarrow \min .
$$

One of the arrangements is a reference-information system. Regional referenceinformation system on normative-legal environmental protection control of Tula region was created. The geoecological monitoring system of Prokop'evsk-Kisilevsk district was created in Kuznetsk Basin. Functional possibilities of automatic monitoring system make it possible to solve following problems:

- researching content and structure of existent database on influence to the environment in the districts of locating enterprises by coking coal mining;

- improvement of natural laws by forming powder-gas emission, liquid and solid wastes and disturbing soil during coking coal mining;

- improving method of evaluating influence to the environment during coking coal mining;

- developing complex software tools making it possible to automatize of environmental influence quality estimation during coking coal mining;

- prognosis estimations of environmental consequences for coal mining development in the Prokop'evsk-Kisilevsk district and in Kuznetsk Basin as a whole.

Analysis information on Prokop'evsk district mines makes it possible to get follow empirical dependence:

$$
J_{i}=\alpha_{1 i}+\alpha_{2 i} A+\alpha_{3 i} E+\alpha_{4 i} t
$$

where $J_{i}$ is the intensity of influence to environmental components; $\alpha_{1 i}, \alpha_{2 i}, \alpha_{3 i}, \alpha_{4 i}$ are empirical coefficients; $A$ is production capacity of the mine, thousand t/year; $E$ is power consumption at the concerned mine during the accounting period, thousand $\mathrm{kW} /$ year; $t$ is time, years; $i$ is an index of influence to environment kind.

Forecasting indexes of anthropogenic influence upon the environment by Coal Company "Prokop'evskugol"' and by enterprises of Kuznetsk Basin Coal industry until the 2025 year are shown in Tables 1 and 2 .

The second region for using proposed monitoring system was Tula Region. Basic mines of Moscow Coal Basin located in Tula Region. Functional possibilities of automatized monitoring system made it possible to substantiate follow theoretical foundations:

- one-parametric dependences of powder-gas emission into the atmosphere from consuming electrical energy dynamics in mining industry regions have got linear form; 
- powder-gas emission into atmosphere dependence from consuming electrical energy dynamics is described by the differential equation of logistic kind;

- functioning "consuming electrical energy - powder-gas emission into atmosphere" system at a priori indeterminacy conditions is simulated with using local mathematical models;

- anthropogenic influence upon the atmosphere of mining industrial region is characterized by consuming electrical energy, which makes it possible to evaluate part of every industrial branch at total powder-gas emission.

Table 1. Forecasting indexes of anthropogenic influence upon the environment by Coal Company "Prokop'evskugol"”.

\begin{tabular}{|l|c|c|c|c|}
\hline \multirow{2}{*}{ Name of the index } & \multicolumn{4}{|c|}{$\begin{array}{c}\text { Forecast index of anthropogenic } \\
\text { influence for existent environmental } \\
\text { protection activity }\end{array}$} \\
\cline { 2 - 5 } & 2010 & 2015 & 2020 & 2025 \\
\hline Coal mining, mln ton & 4.114 & 19.775 & 23.0 & 27.0 \\
\hline Emitting pollutants into the atmosphere, thousand ton & 26.741 & 128.537 & 149.500 & 175.50 \\
\hline Emission liquid wastes, mln $\mathrm{m}^{3}$ & 14.152 & 68.026 & 79.12 & 92.88 \\
\hline Area of derangement soil, hectare & 23.73 & 114.102 & 132.71 & 155.79 \\
\hline Mass of solid industrial wastes, mln ton & 22.97 & 106.088 & 127.65 & 149.85 \\
\hline
\end{tabular}

Table 2. Forecasting indexes of anthropogenic influence upon the environment by enterprises of Kuznetsk Basin Coal industry until the 2025 year.

\begin{tabular}{|l|c|c|c|c|}
\hline \multicolumn{1}{|c|}{ Name of the index } & \multicolumn{4}{c|}{$\begin{array}{c}\text { Forecast index of anthropogenic } \\
\text { influence for existent environmental } \\
\text { protection activity }\end{array}$} \\
\cline { 2 - 5 } & 2010 & 2015 & 2020 & 2025 \\
\hline Coal mining, mln ton & 190 & 218 & 240 & 270 \\
\hline Emission pollutants into the atmosphere, thousand ton & 560.5 & 643.1 & 708 & 796.5 \\
\hline Emission liquid wastes, mln $\mathrm{m}^{3}$ & 260.3 & 298.7 & 328.8 & 369.9 \\
\hline area of derangement soil, hectare & 1265.4 & 1451.8 & 1598.4 & 1798.2 \\
\hline mass of solid industrial wastes, mln ton & 1001.3 & 1148.8 & 1264.8 & 1422.9 \\
\hline
\end{tabular}

Calculation scheme of anthropogenic influence upon environment ensuing analysis material-energetic flows is shown in Fig. 1.

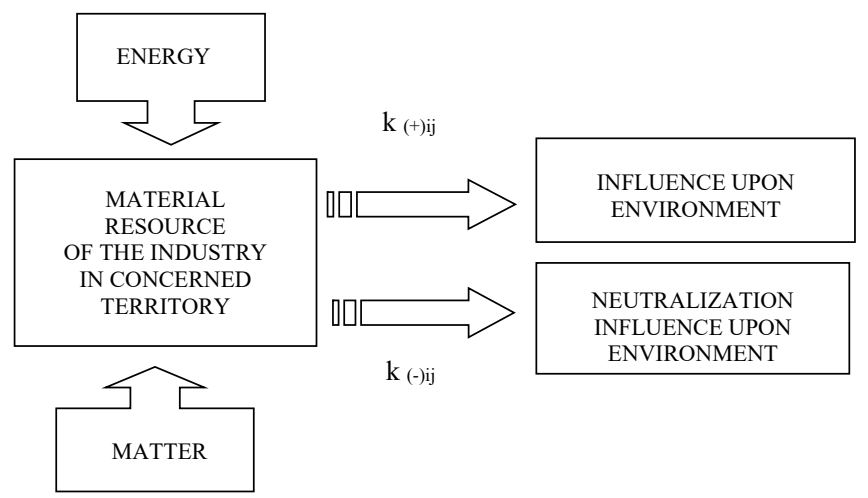

Fig. 1. Scheme of influence upon the environment. 
It is possible two scripts. A first the territory has got the unlimited material resource. A second there is a competition of material resource in this territory. Let intensity of influence upon the environment is $I_{i j}$, where $i$ is the index of the environmental element; $j$ is the index of intensity of environmental influence. Mathematical models of influence upon industry development region environment are shown in Table 3.

Table 3. Mathematical models of influencing industry upon the regional environment.

\begin{tabular}{|l|c|c|}
\hline \multicolumn{1}{|c|}{ Characteristics of the territory } & $\begin{array}{c}\text { The differential equation of } \\
\text { influence upon the environment }\end{array}$ & Initial condition \\
\hline 1. Unlimited material resource & $\frac{d I_{i j}}{d E}=\xi_{i j}\left(I_{i j}^{(\infty)}-I_{i j}\right)$ & $\left.I_{i j}\right|_{E=0}=0$ \\
\hline $\begin{array}{l}\text { 2. Competitive activity for material } \\
\text { resource }\end{array}$ & $\frac{d I_{i j}}{d E}=\varepsilon_{i j}\left(I_{i j}^{(\infty)}-I_{i j}\right) I_{i j}$ & $\left.I_{i j}\right|_{E=0}=I_{i j}^{(0)}$ \\
\hline
\end{tabular}

\section{Results}

Solving these differential equations are theoretical foundations of evaluating environmental situation [20-26]. form:

Solving differential equations of influence upon environment has got the following

- with unlimited material resource:

$$
I_{i j}(E)=I_{i j}^{(\infty)}\left[1-\exp \left(-\xi_{i j} E\right)\right]
$$

- with competitive activity for material resource:

$$
I_{i j}(E)=\frac{I_{i j}^{(\infty)}}{1-\left(1-\varphi_{i j}\right) \exp \left(-\varepsilon_{i j} I_{i j}^{(\infty)} E\right)},
$$

where $E$ is consumption of electrical energy; $\xi_{i j}=k_{i j}^{(+)}+k_{i j}^{(-)} ; \quad \varepsilon_{i j}=K_{i j}^{(+)}+K_{i j}^{(-)}$; $\varphi_{i j}=I_{i j}^{(\infty)} / I_{i j}^{(0)} ; k_{i j}^{(+)}, k_{i j}^{(-)}, K_{i j}^{(+)}$and $K_{i j}^{(-)}$are constants of energy intensity for influence upon environment and neutralization of it accordingly; $I_{i j}^{(\infty)}$ is equilibrium intensity of influence upon the environment; $I_{i j}^{(0)}$ is the initial intensity of influence upon the environment.

Let's use following designations: $R I_{1}\left(e_{1}\right)=R I_{2}\left(e_{2}\right)=I_{i j}(E) / I_{i j}^{(\infty)} ; \quad e_{1}=\xi_{i j} E$; $e_{2}=\varepsilon_{i j} I_{i j}^{(\infty)} E$.

Diagrams of dependences for relative intensity of influence upon environment from the energetic parameter for two scripts are shown in Fig. 2 and 3. 


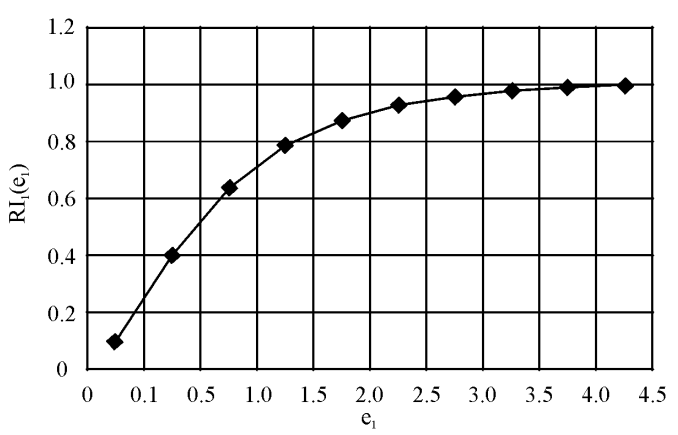

Fig. 2. Diagram of dependence for relative intensity of influence upon environment $R I_{1}$ from parameter $e_{1}$ (with the unlimited resource).

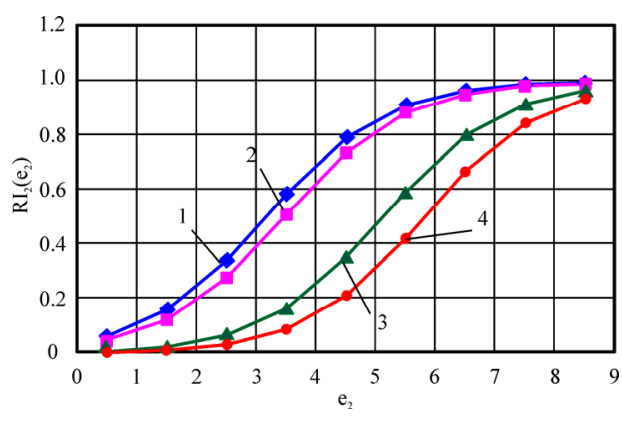

Fig. 3. Diagrams of dependence for relative intensity of influence upon environment $R I_{2}$ from parameter $e_{2}$ (with competitive activity for the material resource) for $\varphi_{i j}$ is equal to follow: $1-15 ; 2-20 ; 3-100 ; 4-200$.

Forecast estimates show that by increasing coal mining this influencing upon atmosphere index on Company "Prokop'evskugol" "enterprises will rise almost in five times in the 2025 year. Forecast indexes of anthropogenic influencing will rise very much in comparison with crisis time highly considerably. Polluting substance mass emitting into the atmospheric air will rise on $55 \%$.

\section{Conclusions}

In conclusion, we want to say follow. People are a major population of the Earth. Our planet is Human ecological niche. Conditions of Human Environment define the quality of their life. Improving environmental monitoring system and creating effective technological actions by neutralization wastes are based on adequate mathematical models of an environmental condition for a territory. These models have to reflect the connection between indexes of public health, influence upon the environment and basic demographic characteristics. Consequently, it is environmental rationally and economical reasonably considering atmospheric air as a natural resource of the mining-industrial region.

Therefore, optimizing technical-economical indexes by atmospheric factor must be based at principals of regulating by institutes of agreement and consolidating mining enterprises with enterprises of others industrial branches. Proposed methodical principals of the complex evaluating atmosphere of mining-industrial region allow realizing integrated approach to forecasting intensity of polluting atmosphere, the economic efficiency of production and atmospheric air condition control with using basic demands of the environmental imperative for considered territory.

Authors express gratitude for the help and consultations during work performing for rector of Kryvyi Rih National University Professor Mykola Stupnik.

\section{References}

1. Golik, V., Komashchenko, V., \& Morkun, V. (2015). Feasibility of using the mill tailings for preparation of self-hardening mixtures. Metallurgical and Mining Industry, (3), 38-41.

2. Golik, V., Komashchenko, V., \& Morkun, V. (2015). Innovative technologies of metal extraction from the ore processing mill tailings and their integrated use. Metallurgical and Mining Industry, (3), 49-52. 
3. O'Sullivan, D., \& Newman, A. (2014). Extraction and Backfill Scheduling in a Complex Underground Mine. Interfaces, 44(2), 204-221.

4. Wang, Weijing, Huang, Shaofeng, Wu, Xiaobo, \& Ma, Qingfei. (2011). Calculation and Management for Mining Loss and Dilution under 3D Visualization Technical Condition. Journal of Software Engineering and Applications, (4), 329-334.

5. Rakishev, B.R. (2013). Complex usage of ore in the enterprises of non-ferrous metallurgy of Kazakhstan. Mining Journal, (7), 67-69.

6. Sekisov, G.V., \& Rasskazov, I.Y. (2014). Creation of a research and production mining and processing complexes for innovative supporting of mining industry. GIAB, (9), 113-121.

7. Kantemirov, V.D. (2014). Technologic features of the development of new raw material bases. GIAB, (6), 369-373.

8. Sokolov, I.V., \& Smirnov, A.A. (2012). About the parameters for computation of ore reserves. Mining Journal, (4), 56-61.

9. Vorobev, V.V. (1995). Efficiency of gaseous additives for explosive materials. In Proceedings of the 1st Ukrainian scientific conference "Industrial explosives and means of their initiation" (pp. 13-15). State Research Institute of Chemical Industry.

10. Komir, V.M., Vorobiev, V.V., \& Napadaylo, V.I. (1991). The effect of gas-forming additive substances in the explosive material on the effectiveness of rock destruction. Blasting work, 90/47. Moscow: Nedra.

11. Haifeng, W., Yaqun, H., Chenlong, D., Yuemin, Z., Youjun, T., \& Cuiling, Y. (2012). Development of Mineral Processing Engineering Education in China University of Mining and Technology. Advances in Computer Science and Engineering. AISC 141. Springer-Verlag, Berlin Heidelberg, 77-83.

12. Bakhtavar, E., \& Shahriar, K. (2007). Optimal ultimate pit depth considering an underground alternative. In Proceedings of Fourth Aachen International Mining Symposia-High Performance Mine Production (pp. 213-221). Aachen, Germany.

13. Capilla, A., \& Delgado, A. (2015). The destiny of the Earth's mineral resources. London: World Scientific Publishing Co. Pte. Ltd.

14. Benardos, A., Athanasiadis, I., \& Katsoulakos, N. (2014). Modern earth sheltered constructions: A paradigm of green engineering. Tunnelling and Underground Space Technology, (41), 46-52.

15. Bowman, S. (2016). Interferometric Synthetic Aperture Radar (InSAR). Back-ground and Application: guidelines for in-vestigating geologic hazards and preparing engineering geology reports, with a suggested approach to geologic-hazard ordinances in Utah. The University of Utah, 198-203.

16. Morkun, V.,Tron, V., \& Goncharov, S. (2015). Automation of the ore varieties recognition process in the technological process streams based on the dynamic effects of high-energy ultrasound. Metallurgical and Mining Industry, (2), 31-34.

17. Morkun, V., Morkun, N., \& Pikilnyak, A. (2015). The study of volume ultrasonic waves propagation in the gas-containing iron ore pulp. Ultrasonics, (56), 340-343.

18. Morkun, V., \& Tron, V. (2014) Ore preparation energy-efficient automated control multi-criteria formation with considering of ecological and economic factors. Metallurgical and Mining Industry, (5), 8-10.

19. Morkun, V., \& Tcvirkun, S. (2014). Investigation of methods of fuzzy clustering for determining ore types. Metallurgical and Mining Industry, (5), 11-14.

20. Morkun, V., Morkun, N., \& Pikilnyak, A. (2014). The gas bubble size distribution control formation in the flotation process. Metallurgical and Mining Industry, (4), 42-45.

21. Morkun, V., Morkun, N., Pikilnyak, A. (2014). Ultrasonic facilities for the ground materials characteristics control. Metallurgical and Mining Industry, (2), 31-35.

22. Morkun, V., Morkun, N., Pikilnyak, A. (2014). Iron ore flotation process control and optimization using high-energy ultrasound. Metallurgical and Mining Industry, (2), 36-42. 
23. Morkun, V., Morkun, N., \& Pikilnyak, A. (2014). Modeling of ultrasonic waves propagation in inhomogeneous medium using fibered spaces method (k-space). Metallurgical and Mining Industry, (2), 43-48.

24. Morkun, V., Morkun, N., \& Pikilnyak, A. (2014). Simulation of the Lamb waves propagation on the plate which contacts with gas containing iron ore pulp in Waveform Revealer toolbox. Metallurgical and Mining Industry, (5), 16-19.

25. Morkun, V., Morkun, N., \& Tron, V. (2015). Formalization and frequency analysis of robust control of ore beneficiation technological processes under parametric uncertainty. Metallurgical and Mining Industry, (5), 7-11.

26. Morkun, V, Semerikov S., \& Hryshchenko, S. (2014). Environmental competency of future mining engineers. Metallurgical and Mining Industry, (4), 4-7. 